Abstracta Iranica Iranica

Revue bibliographique pour le domaine irano-aryen

Volume 22 | 2001

Comptes rendus des publications de 1999

\title{
Women, Work and Islamism. Zed Books, Londres-New York, 1999, 186 p. biblio. index.
}

\section{Azadeh Kian-Thiébault}

\section{OpenEdition}

1 Journals

\section{Édition électronique}

URL : http://journals.openedition.org/abstractairanica/37214

DOI : 10.4000/abstractairanica.37214

ISSN : 1961-960X

Éditeur :

CNRS (UMR 7528 Mondes iraniens et indiens), Éditions de l'IFRI

\section{Édition imprimée}

Date de publication : 15 mai 2001

ISSN : 0240-8910

\section{Référence électronique}

Azadeh Kian-Thiébault, « Women, Work and Islamism. Zed Books, Londres-New York, 1999, 186 p. biblio. index. », Abstracta Iranica [En ligne], Volume 22 | 2001, document 591, mis en ligne le 17 février 2010, consulté le 13 octobre 2020. URL : http://journals.openedition.org/abstractairanica/37214 DOI : https://doi.org/10.4000/abstractairanica.37214

Ce document a été généré automatiquement le 13 octobre 2020.

Tous droits réservés 


\title{
Women, Work and Islamism. Zed Books, Londres-New York, 1999, 186 p. biblio. index.
}

\author{
Azadeh Kian-Thiébault
}

1 L'ambition de ce livre, fondé sur des recherches de terrain menées par son auteur, notamment entre 1989 et 1996, est de "combler le vide laissé par l'attention que beaucoup d'ouvrages sur les femmes iraniennes ont porté à la question idéologique au détriment de l'interaction entre l'idéologie, l'économie et le genre ». Notons que n'étant pas francophone, l'auteur n'a pas eu accès à des recherches, pourtant non négligeables, publiées en langue française sur ce même sujet. L'auteur souhaite mettre la question féminine au centre et non plus à la périphérie de l'analyse de développement et insiste sur l'importance de la mobilisation des femmes contre l'idéologie patriarcale. M. Poya montre que les réponses des femmes ont été influencées par leur origine sociale et leur degré de religiosité. Le premier chapitre conclut que pendant la première phase de l'islamisation (1979-81) la politique menée par le régime islamique concernant la question féminine et l'emploi des femmes combinée à la dépression économique et aux changements des lois, des régulations, des pratiques ou des coutumes a conduit à une baisse de demande pour le travail des femmes. Pendant la même période, l'État islamique a renforcé les relations patriarcales en créant dans le domaine publique des sphères séparées pour les femmes. Quant à la deuxième période de l'islamisation (1981-89), l'État a utilisé la guerre pour légitimer son hégémonie. Néanmoins, les circonstances économiques des années de guerre ont affecté les attentes des femmes, les rapports familiaux et la position des femmes sur le marché de l'emploi. La demande pour leur travail a augmenté d'autant que leur revenu est devenu nécessaire pour le bien-être de leur famille. Pendant cette période, l'État a, d'une part, mis en marche des mécanismes visant à encourager l'activité féminine, d'autre part, tenu un discours idéologique de l'État selon lequel la place des femmes était au foyer. Ces mécanismes ont été utilisés pour entraver l'ascension sociale des femmes actives. Dans les années 1990, sous les pressions socio-économiques et la mobilisation des femmes, l'État islamique a assoupli les mesures qu'il avait adoptées pour contrôler la 
position des femmes dans la sphère publique. L'auteur conclut que la participation des femmes aux activités politiques et économiques a augmenté leur conscience de genre, notamment parmi la jeune génération qui défie les relations patriarcales. Les réponses individuelles et organisées des femmes étaient complémentaires. Ensemble elles ont généré la conscientisation des femmes et dans le cadre islamique ont transformé les rapports entre les sexes.

INDEX

Thèmes : 12.1. Iran

\section{AUTEURS}

AZADEH KIAN-THIÉBAULT

CNRS - Paris 